THURSDAY, MAY 30, 1872

\section{BOTANY IN THE OXFORD NATURAL SCIENCE SCHOOL}

THE merits and demerits of the "Notice by the Board of Studies for the Natural Science School of the University of Oxford" will by this time have been abundantly discussed among all circles of teachers of Natural Science. That the former preponderate over the latter will hardly admit of a question; and if we once more call attention to the defects of the present "Notice," it is only in order that, by full and free discussion, a thoroughly satisfactory scheme may be at length elaborated. We have already pointed out the subordinate part which Botany plays in the programme, and this defect it is our present object to illustrate more at length. We imagine that the object of the framers of the scheme must have been to lay down in the Preliminary Honour Examination a foundation which will serve to give a solid basis for any superstructure that may be raised upon it-in other words, to supply the student with an adequate mental training to prepare him for whatever special branch he may afterwards take up. Let us see how this works in the case of Botany. The Natural Sciences which will be most useful to the future botanist in enabling him to gain a comprehensive insight into his own subject, are the outlines of Animal Physiology, 'Geology, and Organic Chemistry. Of not one of these subjeets need he necessarily possess any knowledge in order to pass the Preliminary Honour Examination; but, on the other hand, must read up Mechanics, Physics, and Inorganic Chemistry. It seems to us a mistake to make the physical side of Science of such preponderating weight in the preliminary examination, to the entire exclusion of the biological.

If we now turn to the Final Examination in Biology, we still find that although it is specially stated that under Biology are included both Zoology and Botany, yet that his own special subject is still kept entirely in the background. Among the "list of books recommended for use in the preparation for the General Examination in Biology" are a number in General Anatomy and Histology, Comparative Anatomy, Human Physiology, Comparative Physiology, and the General Philosophy of Biology, but not one in any department of Botany, with the exception that in a foot-note we are informed that under the term "General and Comparative Anatomy and Histology" "vegetable structures" are included. Otherwise the examination is exclusively one, not in Biology, but in Animal Physiology and the Comparative Anatomy of Animals. The works, indeed, on this subject to which the intending botanist is referred would require a very long course of study to master. The list is so extensive, and the range so great, that it must necessarily have the effect of deterring many an aspirant for distinction in the Natural Science School.

The arrangements under the special subject of Botany seem to us no less open to objection. The first impression conveyed is that the subject can only have been admitted at all under protest, and that it is looked upon as of decidedly subordinate importance to all the rest. While Mineralogy and Crystallography have three pages devoted vor. VI. to them, Geology five, and Zoology four, Botany is compressed into one, and the information and assistance given is of the most meagre. The books " provisionally recommended " are ten in number; but what is meant by a provisional recommendation we do not know. The Board must surely have made up its mind as to whether the works are to be recommended or not; and we venture to say that some even of these ten are books that ought not to have obtained the sanction of such a body. Not only does the list err on this side; but books which are familiar to every botanical teacher as the best elementary works are not to be found in it. It must be remembered that, as far at least as structural and systematic botany are concerned, the studerit is now at the outset of his career; and yet what will be thought of a list of books recommended to his notice which makes no mention of either Oliver's "Lessons" or Lindley's "School Botany"? In Geographical and Geological Botany, the recommendations comprise the portions bearing on these subjects of Henfrey's "Elementary Course" and Balfour's "Manual of Botany." Now, we think it is generally admitted that these'are the least satisfactory portions of the works quoted; and we have no hesitation in saying that the student will gain from them no adequate knowledge of the present state of these sciences. Not a hint is given of the existence of original memoirs or essays, such as those of $\mathrm{De}$ Candolle, Grisebach, Heer, Unger, Hooker, and Carruthers. Again, in the other special subjects the excellent practice is adopted of referring students to monographs or treatises on special branches of the subject, which will not be the least instructive part of his reading. In the botanical list we find no reference even to works so familiar to every student as Mohl "On the Vegetable Cell," Hofmeister "On the Higher Cryptogamia," or the writings of Robert Brown. We venture to say that from the careful study of any one of these works, or even of such smaller treatises as Dr. Hooker's lecture on "Insular Floras," or the introductory essay to his "Flora of Tasmania," the student will gain a deeper insight into the philosophy of his science than from the greater number of the books in the recommended list.

But the greatest defect in the botanical section we take to be the very small stress that appears to be laid on practical work. In accordance with the prominence which is given throughout the whole scheme to histology, it is true that the candidate will be tried with "dissections and descriptions of preparations, illustrating the minute structure and organs of plants ;" but he is not informed that his practical acquaintance with morphology and the principles of classification will be tested by requiring him -as is done at all the examinations at the University of London, constituting the most fruitful source of "pluck"to describe and refer to their natural orders plants presented to him in the room. We the more lament this omission, because it will but have a tendency to confirm the low estimate in which the science of Botany is held even by many biologists, who look upon it as a mere science of terms, leading to no large and comprehensive principles, and susceptible of indefinite "cram." Until Botany is rescued from this degrading position, and teachers learn that it is as much a science of experiment and observation as Animal Physiology or Comparative Anatomy, we shall always have to lament the dearth of 
philosophical botanists so remarkably exhibited in this country at the present time; and to hear it spoken of even by biologists with a covert conternpt.

We make these comments with no desire to detract from the great work which the Board of Studies for the Natural Science School at Oxford is doing, in attempting to elevate Natural Science to a prestige equal to that of theolder studies at our national universities. In this endeavour we wish them heartily all success, and are fully sensible of their earnest$\mathrm{n} \in \mathrm{ss}$ to effect this object. But in order to secure success, it is necessary that any mistakes in the early steps must. be freely and candidly pointed out, and that the plan of the campaign must be made as faultless as possible. We know that there are those at Oxford who are fully sensible of the deficiencies in the programme to which we have called attention, and who have fought a losing battle for a more thorough and comprehensive, and at the same time more eclectic, plan. We would encourage those to persevere in their endeavours, believing that they must ultimately prevail, and that from this beginning a scheme of instruction in Natural Science will ultimately arise which will be a model for the whole kingdom.

\section{MOUNTAINEERING IN THE SIERRA NEVADA}

Mountaineering in the Sierra Nernda. By Clarence King. (London: Sampson Low, Marston, Low, and Searle, I872.)

A VERY pleasant admixture of science and personal A adventure, from the hand of one who is evidently a sincere lover of nature, and is giited with considerable descriptive power. Men and manners in the Far West are depicted with much humour; and one chapter, entitled Kaweah's Run, narrating the escape of the author from a couple of brigands who attempted to hunt him down, will show that a Government surveyor's work in America is apt to be more exciting than pleasant. It is a good while since we have read a book so thoroughly unaffected and fresh.; redolent of the clear air of those lofty Sierras where (hear it, ye Alpine climbers, who, in your haunts, daily curse Jupiter Pluvius !) fne weather is the rule. The description of some of Mr. King's scrambles is enough to make the Alpine Club rush off in a body to Mount Whitney; but we cannot help suspecting that his neck would have more than once been safer had he known the rules of that fraternity and carried a good piolet.

Mr. King does not intend his book for a scientific Ireatise, but there are some valuable notes scattered up and down its pages, and with these we must chiefly concern ourselves. The first chapter gives a good sketch of the geology and physical geography of the Sierra Nevada district. It was submerged till Jurassic periods, the ocean shallowing much in the later Triassic time. Then were produced the long mountain waves which stretch from Mexico probably into Alaska, reaching as far east as Middle Wyoming, and forming one broad zone of crumpled ridges, whose westernmost and loftiest member is the Sierra Nevada. Rivers carved the land into cañons, and the sea gnawed its western shores during all the Cretaceous and much of the Tertiary period, in the later part of which the coast ranges were rolled up, facing the Sierra
Nevada, and converting the California valley into a great inlet of the sea. Then, from newer and older ranges alike, began an epoch of furious volcanic activity, till at last the fires burnt low and the greater number went out altogether. To this succeeded a period when, as in North-Western Europe, great glaciers flowed down the valleys, polishing the rocks and leaving behind them a huge trail of moxaine. Now they have shrunk back into snow-fields; and it is only here and there, as about Mount Shasta, that we find any mention of true glaciers in Mr. King's book.

The magnificent cañons, which have more than once been mentioned in the pages of NATURE, are frequently and vividly described. This is the author's opinion of their origin: "Although much is due to this cause (the cutting power of rapid streams) the most impressive passages in the Sierra valleys are actual ruptures of the rock, either the engulfment of masses of great size, as Professor Whitney supposes in explanation of the peculiar form of the Yosemite, or a splitting asunder in yawning cracks. From the summits down half the distance to the plains the cañons are also carved out in broad round curves by glacial action." It may seem presumptuous in one who has never seen the region to differ from $\mathrm{Mr}$. King and his chief, at the same time we cannot help suspecting that here, as in the Alps, it will be shown ultimately that streams have been the principal agents in forming gorges, and that, though they may have been guided by rifts and certainly by joints, no traces of the orisinal fissures can now be found.

Among the scientific "plums" of light description scattered throughout the pudding, we may notice the following:- The granite of some of the mountains of the Yosemite valley exhibits spheroidal structure on a colossal scale, "concentric layers like the peels of an onion each one about two to three feet thick." This structure never descends into the mass for more than a hundred feet. The author notices a peculiar flaky structure on the surface of ice-worn granite (p. 147) developed, as he believes, by the great pressure which it has undergone. A curious case of granite polished by sand friction is also recorded on p. 146 , reminding us of the polished basalt on the shore of Fife. Earth pillars in the cañon of the McCloud glacier (Mount Shasta) are described, "from one to seven hundred feet high, each capped with some hard lava boulder which had protected the soft (trachyte) débris beneath from weakening." A curious cavern in a lava floor in the same region-roughly tubular in. shape and more than half a mile long-doubtless produced, like those in Iceland, by the outburst and escape of the still liquid interior of the hardening stream, is worth notice; as well as the fresh-water deposits of a lake which existed through the Cretaceous and Tertiary periods between the Rocky Mountains and the Blue Mountains of Oregon. Nor must we in conclusion forget the humorous tale of how the author, after being sternly rebuked by the palrontologist of the survey for loving snow-peaks better than fossils, repented and found a cephalopod in the auriferous slates of Mount Bullion, and so determined their age. We note but one desideratum, and that is a map, which we trust will be supplied should the book reach, as we hope it will, another edition.

T. G. BONNEY 